\title{
Impact of Air Transport on the Indonesian Economy
}

\author{
Abdillah Arif Nasution ${ }^{1, *}$, Zul Azmi ${ }^{2}$, Ikhsan Siregar ${ }^{3}$, and Erlina ${ }^{4}$ \\ ${ }^{1}$ University of Sumatera Utara, Department of Accounting, Jl. Prof. T.M Hanafiah Kampus USU P. \\ Bulan Medan 20155, Indonesia Republic \\ ${ }^{2}$ University of Muhammadiyah Riau, Department of Accounting, Pekanbaru-Riau, Indonesia \\ Republic \\ ${ }^{3}$ University of of Sumatera Utara, Department of Industrial Engineering, Jl. Almamater Kampus USU \\ P. Bulan Medan 20155, Indonesia Republic \\ ${ }^{4}$ University of Sumatera Utara, Department of Accounting, Jl. Prof. T.M Hanafiah Kampus USU P. \\ Bulan Medan 20155, Indonesia Republic
}

\begin{abstract}
This study aims to analyze the causal relationship between air transportation and economic growth in Indonesia. The data used are annual time series data from 1990 to 2017 obtained from World Bank. Data analysis method used is method of Vector Error Corection Model (VECM). The results show that there is a relationship between air transport tax and economic growth in Indonesia. Where is the tax of air transport (passenger and goods) and economic growth (GDP). Based on the granger variable or passenger variables test results and the GDP variable indicates that it remains granger-related with significant 1 percent action. Based on these findings it is hoped that further research is suggested to examine the effect of ticket prices or air fares in order to improve economic growth in Indonesia.
\end{abstract}

\section{Introduction}

The development of a region in Indonesia aims to improve the welfare of Indonesian society. For that development requires a proper approach, in order to generate growth with equity, one of which transportation. Transportation is one means that influence the achievement of economic development success in a region. It also serves to improve the integration of the territory of Indonesia. Air transport has become one of the most important modes of transport for medium and long-distance travel. The main infrastructure that handles air transport movement is the airport. Airports in Indonesia become transportation infrastructure that has a very fast development. Demand from passengers is increasing as human mobility increases. The high demand directly affects the airline's flying schedule request.

Although the relationship between air transport and economic activity can be complex and not homogeneous, some theories support the hypothesis that the two systems can be mutually correlated with each other. Theories that dominate the debate on the development

\footnotetext{
*Corresponding author: badinst@usu.ac.id
} 
of the transport sector and the economic implications in general can be divided into neoclassical and endogenous-growth perspectives. Good quality transport infrastructure can facilitate inter-regional trade and the movement of production supporting factors such as labor and raw materials. In the perspective of economic development, if neo-classical theory is correct then the development will lead to the equity of price and income in one and between regions (convergent). While endogenous-growth theory supports other situations where a region with faster economic growth will attract and provide resources for infrastructure development and investment that will then encourage further economic development in the region (divergent) [1]. In its development, the empirical results of both theoretical approaches led to criticisms related to the assessment of the relationship between the development of air transport and the development of the economy. Such criticisms vary but include, among other things, problems in defining and assessing infrastructure size, aggregate biases, lack of consideration of investment quality, limited discussion of how infrastructure is managed and maintained after construction, and the unmeasured causality in the relationship between the two [2]. This paper is not intended to solve all these problems but focus on a particular part of developmental causality in the correlation relationship between the economy and air transport.

\section{Literature Review}

Although transport infrastructure is generally believed to play an important role in determining the competitiveness of a region, there is no agreement in the literature on how to model the relationship between investment in transport and economic development [3]. Much of the literature, based on analysis published by the World Bank, concludes that transport infrastructure contributes to the development of the economy [4]. Over the years, air travel has played an important role in the development of the economy as the use of air transportation is increasing worldwide. In fact, the historical analysis of the transportation trend indicates that the role of air transport mode will continue to increase in the future as people tend to shift to faster and more expensive modes of transportation as their income increases [5].

\subsection{The Effect of Air Transport on the Economy Temporally}

From a meso-economic perspective, investment or expansion of the airport including its facilities, both for passengers and cargo, can generate potential implications for economic development in the area surrounding the airport. The implications of investment in airport infrastructure development can then be divided into four types with different effects over time [6].

- Primary Effects; provides a brief benefit for an area of airport development or development in the region due to employment opening and increasing revenues associated with aerodrome work ie facility design, runway development, terminal construction and hangar, air navigation system installation and so on. These shortterm effects have had limited effect on the region's long-term economic performance.

- Secondary Effects; provide benefits to the local economy from airport operations that require facility maintenance, security, handling check in passengers and goods, ground handling, and so on. These secondary effects can be very important to the local economy in terms of employment, income, and tax revenues for the local Government.

- Tertiary Effects; derived from the stimulus to the local economy the impact of the existence of companies and individuals who have air transport services. This is 
certainly different for companies located in or close to hub cities when compared to those located in the cities spoke or do not have a large airline. Of the two, hubs have advantages over which more preferred aviation options are preferred by business travelers who will travel, but the excess becomes less important for cargo transport that prioritizes on-time delivery. In addition, the hub can also benefit air transport services in the spoke because without the hub-and-spoke structure of long-distance travel will be difficult to do given the hub allows for route interconnectivity.

- Perpetuity Effects; illustrates the fact that economic growth, which begins in a region, will become self-sustaining, sustainable, and even accelerate. The existence of the airport can change the entire economic structure of a region where the production function of the economy in the region can shift to the center. The dynamic influence of the economy from the airport is the most abstract and unquantifiable type of influence. Although there has been little research on this effect, there are many examples that can be seen on small islands whose agricultural-based economy is transformed into tourism destinations, and the growth of high technology industrial areas around major airports, such as at Dulles Airport - Washington and Logan Airport - Boston in the United States and in the M5 Corridor around Heathrow Airport - London in the United Kingdom.

\subsection{Effect of Air Transport based on Input-Output Analysis}

The basis of input-output analysis is an assessment that explains the relationship of transactions and the interrelation between air transport with other economic sectors [7].

Input-output impact modeling can be applied well in specific regions or airports as it depends on regional economic data. Therefore, most of the studies conducted such as the Minnesota Airport Economic Impact Statement [8] and the Boeing Washington Air Impact Study [9] were commissioned by the local Department of Transport. In addition to academic studies, several consulting firms offer tools to evaluate the economic impact of airport infrastructure by combining input-output and land-use techniques. Examples of regional and international studies include the United Kingdom Study based on 1998 data [10], European Studies from 2003 [11] and the World Civil Aviation Impact Study by ICAO using data from 1998 [12]. Much of the research within the scope of the input-output analysis is conducted only in areas with advanced economies as research analysis relies heavily on intensive data on regional inputs rarely available to developing countries.

Although most studies only evaluate direct, indirect, and induced impacts of air transport, it has long been recognized since at least 1948 [13] that in addition to the above three impacts there is one other type of impact that explains the effects of air transport in creating socio-economic benefits more broadly by allowing certain activities such as tourism and commerce to emerge in the midst of the local economy. The impact is enabling impact and is defined as the overall impact on jobs and revenues generated by economic activities that depend on the availability of air transport services. Enabling impact air transport is more difficult to quantify because of uncontrollable variables such as globalization and the influence of government institutions. Thus, research related to these enabling impacts generally combines quantitative and qualitative modeling such as surveys of firms within the coverage area of the aerodrome. The results of the study linked the use of air transport to activities considered to be generated by air transport, ie tourism, trade, local investment, and productivity improvements. Some examples of studies that explain the enabling impact of air transport in the United States, Europe and Southeast Asia are as follows:

- Irwin and Kasarda studied the association of air passengers with employment growth in US cities using a 30-year regression analysis [14]. The results of the analysis show 
that the expansion of air transport network serving the metropolitan area has a significant positive impact on the work in the region concerned, especially in the service sector.

- Button et al. explains the relationship between high-tech jobs with hub airports [15]. In particular, they show that traffic at the aerodrome hub positively influences the creation of high-tech jobs in the area around the airport. The influence, when controlled for population and other characteristics, is greater than in areas with nonhub airports. This study uses Granger's causality test to support the assertion that traffic at airports causes employment growth.

- Research from Button and Taylor explains the relationship between the availability of international aviation services to Europe with new jobs in the economic field in the metropolitan area of the United States [16]. The results of the research analysis indicate that the increase per 1000 airline passengers opened 44 to 73 new jobs in the economic field in the metropolitan area.

\section{Research Methods}

In this study the type of data source used is secondary data, ie data from the (time series) annual during the period of research 27 years. From 1990 to 2017 obtained from World Bank, and from other sites related to this research.

The analysis model used in this research is the Vector Auto regression model (VAR). This model assumes and treats the variable as an endogenous variable. An alternative model of data modeling as a solution. The VAR model is built with a minimizing theory approach in order to capture the economic phenomenon well.

If the variables are not cointegrated, then a standard VAR can be applied which results will be identical to the OLS, after ensuring that the variable is stationary at the same order. If testing proves that there is a cointegration vector, then VECM can be applied for single equation or VECM for system equation.

In this study CRG is not associated with PSR and vice versa. Researchers assume that CRG and PSR have different meanings because in air transportation distribute transportation in the form of passengers and goods (service delivery). And this study only looks at the relationship between CRG / PSR and GDP and vice versa.

Data processing in this research using Eviews 9. Evaluation model VAR model used in this research is VAR with 3 variables. The three variables are Passenger (PSR), Goods $(\mathrm{CRG})$, Gross Domestic Product (GDP), the three variables are expressed in the form of:

$$
\begin{aligned}
& Y_{t}=\alpha_{1 i}+\sum \beta_{1 i} Y_{t-1}+\sum \gamma_{1 i} X_{t-1}+\varepsilon_{t} \\
& X_{t}=\alpha_{2 i}+\sum \beta_{2 i} Y_{t-1}+\sum \gamma_{2 i} X_{t-1}+\varepsilon_{t}
\end{aligned}
$$

$Y \quad:$ Gross Domestic Product

$X_{l}$ : Cargo

$X_{2}$ : Passenger

$\Sigma^{t}$ : Error Term 


\section{Result and Discussion}

\subsection{Test Stationarity}

Each variable for the VAR model or time series must be stationary so as not to create a false estimate result, this study uses Phillip-Perron (PP) as follows:

Table 1. Test Results Stationaryity PP and Johansen Cointegration Test. Source: [17]

\begin{tabular}{lcc}
\hline \multicolumn{1}{c}{ Variable } & Level I (0) & Difference I (1) \\
\hline CRG & & \\
Intercept & -0.6862 & $-6.4854^{* *}$ \\
Trend and intercept & -2.2654 & $-6.5081^{* *}$ \\
None & 0.9025 & $-6.2817^{* *}$ \\
PSR & & \\
Intercept & 2.8886 & $-5.2876^{* *}$ \\
Trend and intercept & 0.5365 & $-5.9769^{* *}$ \\
None & 4.4182 & $-4.8005^{* *}$ \\
GDP & & \\
Intercept & 4.8198 & $-3.1504^{* *}$ \\
Trend and intercept & 1.5158 & $-4.5786^{* *}$ \\
None & 9.8047 & $-1.5769^{* *}$ \\
Cointegration & & \\
None & {$[57.9389](0.000)^{* *}$} & \\
At most 1 & {$[29.4187](0.0273) *$} & \\
At most 2 & {$[11.0348](0.0864)$} & \\
\hline
\end{tabular}

Stationary test results using PP. Table 1 describes the non-stationary CRG, PSR and GDP variables or root units at level I (0) marked by the probability of the three variables greater than the 5 percent significance score. Further stastioneritas stages done at the first difference level and obtained the results that the variable CRG, PSR, GDP has no roots unit at the level of 1 percent. So, the CRG, PSR, and GDP stastioner variables are at first difference level.

Since the variables are stationary at the first difference level, cointegration testing using Johansen-Cointegration Test is required. The goal if there is cointegration then the model used is the VECM model. The results from Table 1 show the presence of cointegration of 2 with a significance level of 5 percent. Therefore, the VECM model is more appropriate to use than the VAR.

\subsection{Optimal Lag Test}

Optimal lag testing is very important in using the time frame model. Lag serves as the length of influence between a variable against other variables. Therefore the optimal length of slackness is seen at the smallest value. Optimal lag results using AIC as follows:

Table 2. Optimum AIC Test Results. [17]

\begin{tabular}{|c|c|}
\hline Lag & AIC \\
\hline 0 & 95.90845 \\
\hline 1 & 95.74008 \\
\hline 2 & 95.79723 \\
\hline 3 & 96.04345 \\
\hline 4 & 96.08408 \\
\hline 5 & 96.13885 \\
\hline 6 & 94.75447 \\
\hline
\end{tabular}




\begin{tabular}{|c|c|}
\hline 7 & 94.32484 \\
\hline 8 & 94.00500 \\
\hline $\mathbf{9}$ & $\mathbf{9 0 . 6 7 9 8 7} *$ \\
\hline
\end{tabular}

Table 2 describes the optimal lag using lag 9 limits resulting in a lag based on AIC of 9 lag. And it appears that the star sign is at lag $9(90.67987 *)$. So, this research uses optimum lag of 9 with the intention that information can be better.

\subsection{Impulse Response Function Test Results (IRF)}

After going through the test phase that has been done above then done impulse response function analysis. Its function is to see the effects and changes of one variable on the variable itself and other variables. By using IRF it can be seen that a variable responds to a change of one standard deviation.
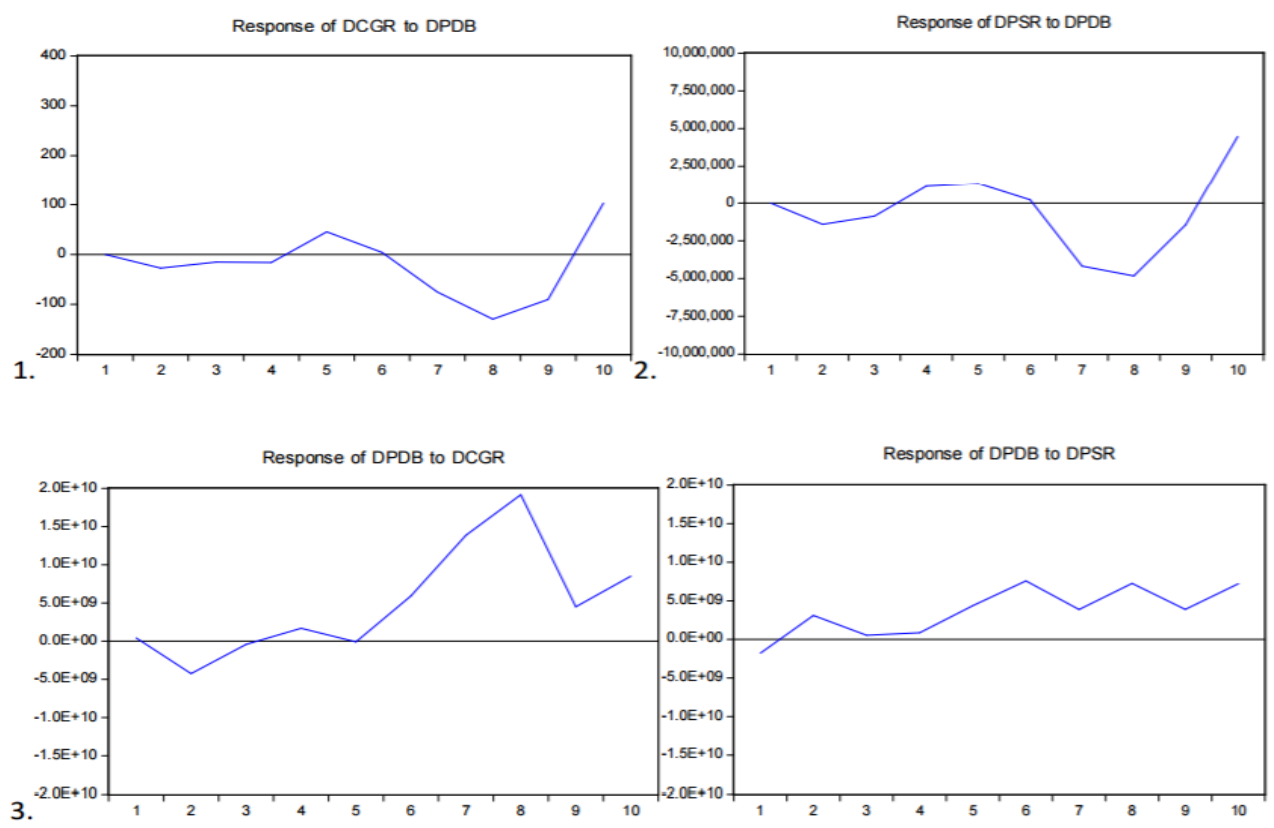

Fig. 1 Impulse Response Function (IRF). Source: [17]

The first response analyzed was the response of CRG variable. From Figure 1 we can see how the response of CRG variable is caused by GDP variable. If we look at the response given in CRG to the change of one standard deviation of the variable itself is positive value of priode 5 which is 50 billion and after that it culminates the downward trend to reach its lowest response level in priode 8 of -100 billion but after that the response rises back and stable until the last period in priode 10 at a response rate of 100 billion.

The response which is then analyzed is the response of PSR variable. From Figure 2 we can see the response given by PSR on the change of one standard deviation of the variable itself and the variable of GDP. In the PSR response to the positive GDP variable of the variable priode 4 that is 2 million. However, after that, the trend of decline to reach the lowest respn in priode 8 of -5 million. After that the response went back up and stabilized in the range of 5 million in period 10 to the final pride of observation. 
The last response analyzed was the response of the GDP variable. From Figure 3 it can be seen the movement of GDP respondent variable due to PSR and GDP variables. Viewing from the deviation of the two variables gives effect to positive GDP from period 4 by CRG and period 1 by PSR. This indicates the economy will continue to grow positively in the next 4 years by CRG and PSR from 1 year ahead. The effect of passenger increase is significant from year to year. Indonesia as an archipelago, the need for air transportation is important for the smoothness of the central and regional activities. Nevertheless, there is considerable cost inconvenience to get a fast time. But the situation of air transportation usage up to now is highly dependent on the cost of ticket by air transport. This is reflected from Figure 1 which explains the passenger variable (PSR) is quite sensitive. Similarly, the effects of cargo (goods) showed that the period of 6 to 8 GDP increased sharply but decreased dramatically in period 9.

\section{Conclusion}

Based on the results of research that has been done, it can be drawn conclusion as follows:

a. There is a good lead relationship or causality between air transport and economic growth. Where air transport is seen in terms of (passenger and goods) and economic growth (GDP), so the variable of passenger or goods and GDP variables indicates that it remains related to granger causality with 1 percent significant action

b. Air transport has become one of the most important modes of transportation for long-distance and long-distance travel and is able to reach from one area to another, geographically difficult to reach by both land and sea transportation modes. As well as the travel time is relatively faster compared to land and sea transportation modes.

\section{References}

1. K.J. Button, The Economist's Perspective on Regional Endogenous Development,. Cheltenham: Edward Elgar Publishing. (2011)

2. C. Winston, Efficient Transportation Infrastructure Policy. Journal of Economic Literature, 5, pp. 113-127 (1991) DOI: 10.1257/jep.5.1.113.

3. L. D. Yeang, D. Banister, and P. Hall. Transport and City Competitiveness - A Literature Review. University College London: U. K. Department for Transport. (2004)

4. Prud'homme. Infrastructure and Development, Annual World Bank Conference on Development Economics 2005: Lessons of Experience,. New York: World Bank and Oxford University Press. (2005)

5. A. Schafer and D. G. Victor. Transportation Research Part A, 34, 3, pp. 171-205.. (2000) DOI: 10.1016/S0965-8564(98)00071-8.

6. K.J. Button, Southampton: WIT Press. (2010)

7. K. R. Polenske and S. F. Fournier. Rutgers University: Center for Urban Policy Research. pp. 205-227 (1993)

8. W. Garner, D. Erkkila, and J. Hyunkuk. Minnesota University. Minnesota Department of Transportation. (2005)

9. W. B. Beyers and S. J. Hyde. Washington. King County Department of Transportation. (2003)

10. Department for Transport. Aviation, Core Cities and Regional Economic Development. London. (2003) 
11. Advisory Council for Aeronautics Research in Europe. Retrieved July 2, 2018,fromhttp://www.acare4europe.org/sites/acare4europe.org/files/document/ACARE _Success_Stories_Final.pdf. (2003)

12. International Civil Aviation Organization. Retrieved July 5, 2018, from https://www.icao.int/Meetings/AMC/MA/2005/ATWorkshop/C292_Vol1.pdf (2004)

13. G. Beckett. Foreign Trade by Air. Journal of Marketing. 12, 4, pp. 505-506. (1948)

14. M.D Irwin. and J. D. Kasarda. American Sociological Review. 56, 4, pp. 524-537, (1991)

15. K.J Button, S. Lall, R. Stough, and M. Trice., Journal of Air Transport Management. 5, 1, pp. 53-59, (1999)

16. Button. K.J and S. Taylor. Journal of Air Transport Management, 6, 4, pp. 209-222. (2000)

17. Eviews 9 (2016) 